\title{
New ideas on the anatomy of the kidney
}

\author{
DB MOFFAT
}

From the Department of Anatomy, University College, Cardiff

A discussion of new ideas on the anatomy of the kidney presents some difficulties, firstly in defining what is meant by "anatomy" and secondly in selecting which particular new ideas to present. Bowman, ${ }^{1}$ perhaps, answered the first question not only by describing the structure of the glomerulus and tubules but also by discussing the functional significance of his findings. Nowadays the scope of such functional anatomy needs to be expanded to include biochemical anatomy so that the choice of subjects becomes even more difficult. I have chosen two features of the glomerulus - namely the glomerular filter and the mesangium, because these are of such importance in understanding the pathology of the kidney - and two features of the renal medullaits blood supply and its interstitial tissue, because these offer interesting subjects for speculation on possible future developments.

\section{The glomerular filter}

From an anatomical point of view, this consists of the capillary endothelium, the glomerular basement membrane (GBM) and the filtration slit between the bases of the foot processes of the epithelial cells or podocytes. Until recently, the clearance values of macromolecules were interpreted, not entirely successfully, in terms of a mechanical filtering effect but it has become increasingly evident that the biochemical make-up of the filter, including the composition of the GBM and of the cell coat of the endothelial and epithelial cells, is of fundamental importance.

\section{CAPILLARY ENDOTHELIUM}

The capillary endothelium offers no anatomical barrier to the passage of even the largest molecules. It is a fenestrated endothelium but the diameters of the fenestrations are between 50 and $100 \mathrm{~nm}$, very much larger than any of the macromolecules in the plasma. Also, unlike the fenestrations in other capillaries, the openings are not closed by a membrane (except in the developing glomerulus) so that the capillary blood comes into direct contact with the GBM. The endothelial cells have, however, a negatively charged cell coat which is up to $12 \mathrm{~nm}$ in thickness.
GLOMERULAR BASEMENT MEMBRANE

The human GBM is $250-350 \mathrm{~nm}$ thick. In electron micrographs three layers can be distinguished, a central lamina densa (LD) with a less dense lamina rara interna (LRI) on the endothelial side and a lamina rara externa (LRE) on the side of the podocytes. It has a fibrillar structure ${ }^{2}$ but no "pores" are visible, and when large molecules such as ferritin pass through it no tracks can be seen. Space does not permit a full account of the chemical make-up of the GBM but the most important features are that it has collagenous and non-collagenous components, is rich in carbohydrates, and contains glycosaminoglycans including sialic acid $(2 \%)$ and heparan sulphate. It is therefore strongly anionic and has characteristic staining properties. Thus it stains intensely with periodic acid-Schiff (PAS) and with cationic stains such as Ruthenium red, alcian blue and colloidal iron. Suitable modifications of these staining methods make it possible to demonstrate the actual anionic sites in the GBM. Kanwar and Farquhar $^{3}$ administered cationised ferritin intravenously to rats followed by fixation by perfusion, and they also used Ruthenium red added to the fixative as a cationic label. They found clusters of electron-dense particles in both laminae rarae and in the mesangial matrix. These formed a fairly regular lattice-work with the centres of the clusters about $60 \mathrm{~nm}$ apart. When both cationic markers were used together, they localised at the same points in the GBM. Recent work by the same authors has shown that these anionic sites consist of glycosaminoglycans, mainly heparan sulphate. This was shown cytochemically by appropriate enzyme digestion in vivo $^{4}$ and by cellulose acetate electrophoresis of the isolated GBM. ${ }^{5}$ The importance of this highly charged polymer in glomerular permeability will be discussed later.

\section{EPITHELIAL CELls (PODOCYTES)}

The epithelial cells are arranged around the capillaries, and their foot processes interdigitate to give the glomerular filtration membrane its characteristic appearance. The foot processes are partly embedded in the GBM, and the space between their bases is the filtration slit or slit pore, and has a width of 
20-30 nm. It is closed by a membrane (the slit diaphragm) which is clearly seen when sectioned transversely; sections tangential to the GBM, however, show that the diaphragm has a complex structure. ${ }^{67}$ After fixation with a tannic acidglutaraldehyde fixative, a central bar can be seen running along the slit, with alternating light and dark areas on either side of it, so that the whole slit resembles a zipper. The light areas may represent openings and measure approximately $4 \times 14 \mathrm{~nm}-$ about the size of the albumin molecule.

The outer surface of the podocytes is covered by a strongly anionic cell coat which is sufficiently thick $(15-80 \mathrm{~nm})$ to fill the filtration slit completely so that it covers the outer surface of the slit diaphragm. The cell coat, like the GBM, stains strongly with various cationic dyes. The foot processes, when cut transversely, have a characteristic "elephant's foot" shape, being much wider at the base than at the summit but after some types of fixation their lateral sides are parallel along their whole length so that it is possible that in vivo the cell coat fills the whole space between the foot processes. ${ }^{2}{ }^{8}$ The presence of the polyanionic cell coat may well be responsible for maintaining the shape and interrelationship of the foot processes by their mutual repulsion, as will be discussed later.

The podocytes themselves are phagocytic, as has been shown by a number of workers, and their cytoplasm contains fine filaments that resemble myofilaments. They have been shown to contain actin and heavy meromysin and may therefore be contractile. ${ }^{9}$ The cytoplasm also contains a large number of microtubules. These, in other cells, have various functions including that of forming a skeleton to maintain the shape of the cells. Tyson ${ }^{10}$ and Andrews ${ }^{11}$ destroyed the microtubules in rat podocytes with vinblastine and found changes in podocyte shape, although the foot processes themselves were not affected.

FILTRATION PROPERTIES OF THE

GLOMERULUS

During the last few years, knowledge of the process of glomerular filtration has increased rapidly as new methods of study have become available. Until relatively recently, the filtration properties of the glomerulus were thought to be mainly a function of molecular size and, to some extent, of shape, and were studied by clearance methods and electron microscopy, using a whole spectrum of molecules with molecular weights ranging from 12000 (equine cytochrome C) to $\mathbf{4 8 0} 000$ daltons (ferritin). These experiments, reviewed by Rennke and Venkatachalam in $1977,{ }^{12}$ led to the idea that while some large molecules are held up by the GBM, smaller molecules are able to penetrate as far as the slit diaphragm or beyond. The strongly anionic nature of the components of the filtering membrane suggested that molecular charge as well as size might have an effect on the filtration of macromolecules and this was shown to be true in 1975 by Chang et al, ${ }^{13}$ who compared clearance values for dextran and dextran sulphate, and by Rennke et $a l,{ }^{14}$ who studied the filtration of ferritins with different isoelectric points by electron microscopy. The results of such studies by these and other workers showed that while molecular size is obviously an important factor, cationic molecules penetrate the filtration membrane very much more freely than neutral or anionic molecules of a similar molecular weight (see review by Karnovsky). ${ }^{8}$ The most recent contribution to this field is that of Kanwar et $a l^{15}$ who followed up their demonstration of heparan sulphate in the GBM by studying the effect of its removal by heparinase, using native ferritin as a tracer. In control animals the ferritin did not penetrate beyond the lamina rara interna to any great extent but after heparinase treatment it traversed the GBM freely and was found in the urinary space.

A review of the filtration properties of the glomerulus is not complete without reference to haemo dynamic factors although this is not strictly are anatomical problem. However, the laboratory rats in which this has been studied do have an interesting and useful feature which might well be classified as a "new idea in anatomy." Munich-Wistar rats, which originated in Munich but are now found in every laboratory in which glomeruli are studied, have a small number of glomeruli on the surface of the kidney where they can be seen quite easily and are available for micropuncture. Ryan and Karnovsky ${ }^{16}$ have studied the filtration of endogenous albumin by an immunoperoxidase technique. The visible glomeruli were fixed during normal activity by dripping the fixative on to the surface of the kidney. Under these conditions it was found that albumin was held up at, or just beyond, the endothelial fenestrations. If, however, the kidneys were fixed by immersion, or if the circulation was interrupted before fixation, albumin was found in the GBM and in the urinary space. Similar results were found using catalase and endogenous IgG (MW 240000 and 150000 daltons respectively), although these materials did not reach the urinary space. ${ }^{17}$

Finally, for the sake of completeness, it must be mentioned that other haemodynamic factors also are involved and the fractional clearance of large molecules is partly dependent upon the determinants of the glomerular filtration rate. ${ }^{18}$ 


\section{OTHER FUNCTIONS OF GLOMERULAR}

\section{POLYANION}

Further aspects of the importance of glomerular polyanion can be studied by removing or blocking it, thus causing the loss of the fixed negative charge. This has been done, for example, by perfusion with cations such as protamine sulphate, ${ }^{19}$ by treatment of kidney slices with neuraminidase which removes sialic acid ${ }^{20}$ and by the culture of isolated glomeruli in the presence of polycations. ${ }^{21}$ These processes all have effects which mimic those of human and experimental nephroses including cell swelling, the loss of separate and distinct foot processes, the formation of junctions between foot processes and changes in the slit diaphragm. Numerous other workers have studied the glomeruli in human and experimental glomerulopathy and have shown a correlation between loss or fusion of foot processes, decrease of polyanion, and proteinuria. ${ }^{8}$ These observations suggest that the foot processes may be held apart by the electrostatic repulsion of their fixed negative charges and that the loss of polyanion will lead to the "fusion" of foot processes and will increase the permeability of the glomerular filter, thus leading to proteinuria. Reeves et $^{2} \mathbf{l}^{22}$ have recently produced some interesting evidence in favour of this hypothesis in their study of glomerular development. Examination of 2 to 5 day-old rat kidneys, in which glomeruli at all stages of development can be studied in the nephrogenic zone, showed that in the early stages of development the polyanionic cell coat of the epithelial cells only stains faintly and only extends down to the occluding junctions that unite the foot processes at this time. The development of normal, separated foot processes coincides with the development of a full cell coat around the entire lateral surfaces of the processes.

In addition to its probable function in maintaining normal filtration slit architecture, the glomerular polyanion may also be of importance in attaching both endothelial and epithelial cells to the GBM. Kanwar and Farquhar ${ }^{23}$ perfused rats with neuraminidase for $30-60$ min before fixation for electron microscopy. The endothelial cells and the foot processes became detached from the GBM and their normal staining with colloidal iron was lost. Free sialic acid was found in the bladder urine. After a long perfusion, large areas of the GBM were denuded of cells and the mesangial cells became detached from the matrix. The GBM, however, showed normal cationic probe binding, and removal of its heparan sulphate had no effect on the attachment of cells. It was surmised that the attaching agent might be fibronectin, a large glycoprotein molecule containing sialic acid, or possibly laminin, which also contains sialic acid. In a footnote, the authors state that they have succeeded in locating fibronectin in the glomerulus, and it has also been produced in vitro by cultured glomerular cells. ${ }^{24}$ Recently, however, Madri et al ${ }^{25}$ found fibronectin only in the mesangial region of mouse kidneys while laminin occurred in the mesangium as well as in the lamina rara interna and the adjacent area of the lamina densa of the glomerular basement membrane.

\section{The mesangium}

The mesangial region, the central core of tissue in the glomerulus, consists of an extensive matrix in which irregular cells with numerous processes are embedded. At one time the existence of these cells was doubted, but with the advent of electron microscopy and, more recently, as a result of experimental studies, it has become evident that the mesangium is a dynamic and important component of the glomerulus which is the focus for many disease processes. In order to explain the relation between the mesangium and the GBM it will first be necessary to say a little more about the GBM itself. It is a compound membrane, being formed by the basement membranes of both the endothelium and the epithelium which fuse to produce the threelayered GBM when the developing glomerulus is at the S-shaped body stage. ${ }^{22}$ Huang ${ }^{26}$ has recently shown that these two components can be distinguished by treatment with $5 M$ guanidine hydrochloride before fixation. The endothelial component and the mesangial matrix are then found to be less electron-dense than the epithelial component. After this treatment it can be seen that the epithelial basement membrane is a continuous layer that partially covers each capillary tuft by being wrapped around it and being invaginated between individual capillaries. It does not, however, completely encircle any capillaries, being absent over the region of the capillary wall that is adjacent to the mesangium. In this region, therefore, the endothelial basement membrane is continuous with the mesangial matrix so that here there is a low permeability route from the capillary lumen to the mesangium.

The mesangial cells are scattered in the matrix, leaving channels of matrix between them which may serve as one of the routes for the passage of materials through the mesangium. The cells appear to te active, for they contain a fairly prominent Golgi zone, a good deal of endoplasmic reticulum, glycogen and mitochondria. They also contain microfilaments which are probably contractile (see below). They are, in fact, very similar to smooth muscle cells and this similarity is emphasised by their contiguity with the lacis cells of the juxtaglomerular 
apparatus (JGA) and the smooth muscle cells of the afferent and efferent arterioles. ${ }^{27} 28$ Christensen ${ }^{29}$ examined the JGA from 49 human glomeruli and found contiguity with the mesangium and the lacis cells, with a gradual transition of cell types from one to the other. A number of investigators ${ }^{30}$ have found that the cells of the mesangium and of the JGA are interconnected by gap junctions so that they may act together as a syncytium, their contraction perhaps affecting the glomerular blood flow.

\section{CONTRACTILITY}

There seems little doubt that the mesangial cells are contractile. Their microfilaments have been mentioned already and immunoelectronmicroscopic studies have demonstrated the presence of actomyosin in the cells and also in the matrix of glomeruli both in situ and in cultures. ${ }^{31-33}$ Whole glomeruli in cultures have been seen to contract ${ }^{34}$ while more recently Mahieu et $a l^{35}$ and Ausiello et $a l^{36}$ have been able to show contraction of presumed mesangial cells from cultured rat glomeruli, after stimulation with angiotensin II, noradrenaline and arginine vasopressin. Osborne $e t a^{37}$ have shown that after the injection of ${ }^{3} \mathrm{H}$ angiotensin II into rats, radioactivity was localised mainly in the mesangial cells. It seems likely that the angiotensin interacts with some specific site within the cells, although other explanations are possible.

\section{FATE OF LARGE MOLECULES}

The mesangial region is of particular interest in renal disease because of its ability to take up and dispose of large molecules, particularly immune deposits, so that the rates of entry and exit of such molecules have been the subject of much investigation. The molecules are presumed to enter the mesangial region mainly via the "bare area" of the capillary wall where the main GBM is absent. The factors that control this afferent limb have been admirably reviewed by Michael et $a l^{38}$ and only the anatomical aspects of the processes will be discussed here.

Many workers have studied the passage of large molecules into the mesangium by light and electron microscopy, using such tracers as colloidal gold, dextrans, ferritin and colloidal carbon. The fate of these substances depends on the molecular size but in all cases the particles pass into the mesangial matrix and some, at least, are taken up by the mesangial cells. Recent works have shown the importance of the contiguity of the mesangium with the JGA. Elema et al, ${ }^{39}$ for example, used colloidal carbon and showed that the uptake of particles by the mesangium was maximal at $32 \mathrm{~h}$ after the injection and that the carbon first entered the channels between the cells. Thence, it was taken up by the mesangial cells and was apparently passed on from cell to cell to the lacis region where it was found 2-7 wk after the injection.

There is a good case for classifying the mesangium as part of the reticuloendothelial (RE) system but with a time-lag. Thus, the uptake of injected material by the mesangium lags behind that of the RE system and, for this reason, is dose-dependent. A small dose is taken up relatively avidly by the RE system and accumulation in the mesangium will not occur unless the RE system is partly saturated and the blood level rises. Similarly, after the material has reached the mesangium, it subsequent disappearance lags behind the fall in blood level.

The size of the molecules also affects the fate of particles in the mesangium. Many workers have noted that very large molecules such as immune complexes and aggregated proteins tend to be found in the matrix with relatively little phagocytosis. This is not invariably so, however, and, since space does not permit a full discussion of the subject, two of the most recent papers will serve to illustrate the problems. Takamiya et al ${ }^{40}$ compared the effects of injections of native ferritin and ferritin complexed with IgG and albumin. There was a very clearly dose-dependent accumulation of ferritin in theo mesangium, the conjugates requiring a much smallers dose than native ferritin to produce maximalo mesangial concentration. Native ferritin was cleared almost completely in 14 days but the conjugate was still very evident in the mesangium, mainly within the cells. They also showed that, when the conjugate had disappeared from the blood but was still present in the mesangium, injected rabbit antiserum to ferritin became localised in the mesangium, showing that the mesangial cells are accessible to circulating antigens. Lee and Vernier ${ }^{41}$ used aggregated human albumin as a marker and found it in the matrix within 40 min of administration, with maximal accumulation at $8 \mathrm{~h}$. There was some uptake by mesangial cells but there always appeared to be more in the matrix channels than within the cells. The aggregated albumin was also found between the lacis cells and within the walls of arterioles as early as $4 \mathrm{~h}$ after injection.

The fate of mesangial deposits after reaching the JGA region or after phagocytosis by the cells is not known but it is worth mentioning a recent investigation by Albertine and $\mathrm{O}^{\prime}$ Morchoe $^{42}$ who studied the cortical lymphatics in the dog kidney. In contrast to a number of previous workers, they were able to demonstrate an intralobular distribution of lymphatics, including some in close relation to the JGA (which may, incidentally, explain the high renin concentration in the renal lymph). It is possible, 
therefore, that the lymphatic system may receive the end products of mesangial processing.

\section{The intrarenal blood vessels}

The distribution of the main arteries has been well documented, as has that of the smaller vessels in various animals, ${ }^{43-45}$ but it is only recently that a detailed study of the small vessels in the human kidney has been made using modern techniques. ${ }^{46} 47$ The origin of the afferent arterioles and the distribution of the efferent arterioles are very similar to those of animals, and Beeuwkes classified the efferents into 10 types according to their position in the cortex and their distribution. He has also perfected an elegant technique in which both vessels and tubules are injected with coloured silicone rubber (Microfil, Canton Biomedical Products) so that the vascular-tubular relationships can be studied. In the subcapsular cortex, the proximal and distal tubules of any one nephron are usually supplied in part by the efferent vessel of the corresponding glomerulus but this association is not as marked as in the canine kidney, which Beeuwkes has also studied. In the middle and inner zones of the cortex the convoluted tubules and the loops of Henle are almost completely supplied by the efferents of other glomeruil and, in general, each nephron receives blood from many glomeruli, each efferent supplying a short segment. This lack of a 1:1 efferent arteriole: nephron relationship throws some doubt on certain theories of glomerulotubular balance based on hydrostatic and oncotic capillary pressures.

\section{BLOOD SUPPLY OF THE MEDULLA}

The blood supply of the human medulla has been studied in four human kidneys. ${ }^{46}$ The main blood supply is derived from the efferent arterioles of the juxtamedullary glomeruli. These descend into the medulla by looping around the arcuate vessels, giving small branches to the loose capillary plexus in the subcortical region (also known as the outer stripe of the outer medulla). Near the arcuates, each efferent arteriole breaks up abruptly into a large number of descending vasa recta (DVR) which are of almost the same size as the parent vessel (Fig. 1). The number of DVR from each efferent arteriole varies between 12 and 25 but, since each bundle of DVR receives branches from a number of efferents, the number in each bundle may be as many as 50 . As the bundles traverse the outer medulla, vessels leave the periphery of the bundle to supply the local capillary plexus, while rather more DVR leave the bundles as they enter the inner medulla. The bundles therefore soon lose their identity in the inner medulla but some of the DVR continue their course, unbranching, to various levels in the papilla before breaking up into capillaries.

From the elongated capillary plexus of the inner medulla, venous vessels collect tributaries and form

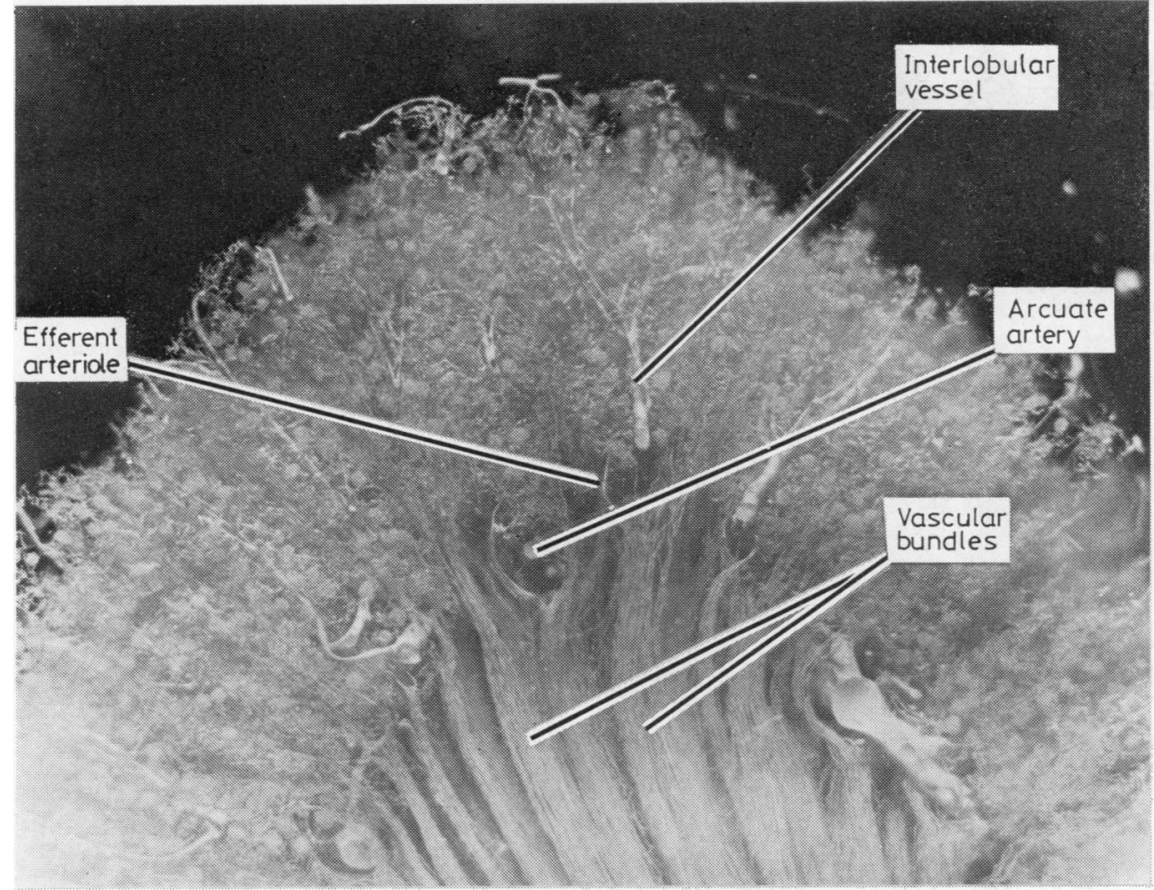

Fig. 1 Human kidney, Microfil injection. Only the descending vasa recta have been injected, the ascending vasa recta remaining unfilled. 
ascending vasa recta (AVR) and in the outer medulla these become closely intermingled with the DVR to form vascular bundles. These are a very prominent feature of the outer medulla and since the numbers of descending and ascending VR are approximately equal in the human kidney, each bundle may contain up to 100 vessels. There is no evidence that the descending limbs of the loops of Henle are incorporated into the vascular bundles as they are in many animals. The bundles receive additional AVR that drain the capillary plexus of the outer medulla and they then drain into the arcuate or interlobular veins.

\section{FINE STRUCTURE OF THE VASCULAR}

BUNDLES

In the upper part of the vascular bundles the DVR, like the juxtamedullary efferent arterioles, have a layer of smooth muscle in their walls (Fig. 2) and they are accompanied by non-medullated nerves that lie in close proximity to the vessel walls. In between these relatively thick-walled DVR are the wide AVR whose wall is composed only of an extremely thin fenestrated endothelium. In the deeper parts of the outer medulla the descending vessels lose their smooth muscle and with it their accompanying nerves. They are surrounded by perivascular cells; these are thin cells that are wrapped around the descending vessels and have a layer of microfilaments on the side facing the DVR and a row of micropinocytotic vesicles on the side adjacent to the AVR. In many places the perivascular cells are absent so that the descending and ascending vessels come into very close contact. The structure of the vasa recta thus suggests a regulatory function in the upper part of the vascular bundles and a countercurrent exchange system lower down.

An accessory blood supply to the papilla is derived from a number of caliceal vessels that arch over the fornix to supply the most superficial layers of the papilla. The functional significance of this blood supply is difficult to assess but it is interesting that Heaton and Bourke ${ }^{48}$ have described a case in which acute arteritis of these vessels appeared to be a cause of papillary necrosis. They are certainly vulnerable to ruptures of the calicine fornices such as occur when the calices are strongly distended for any reason.

There is a great deal of experimental evidence for

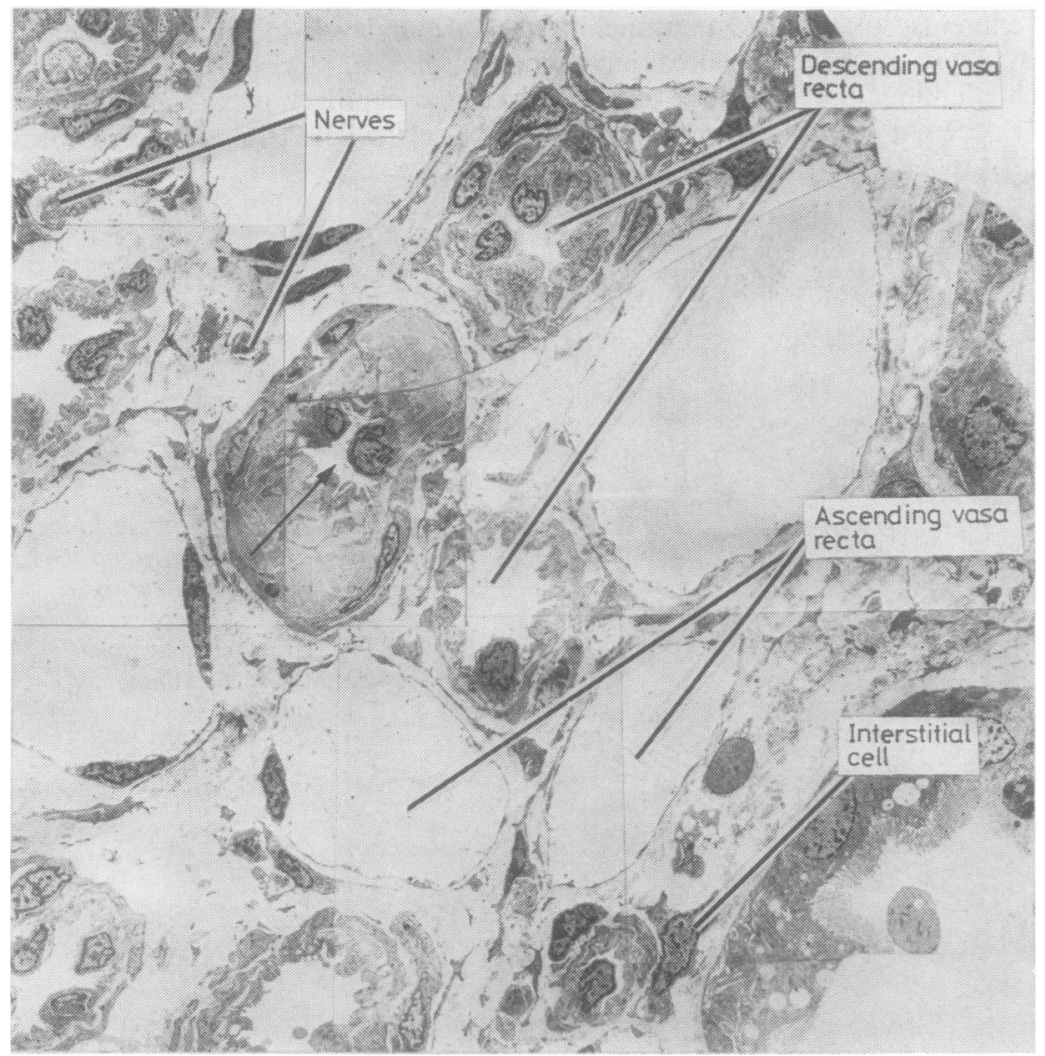

Fig. 2 Human kidney, vascular bundle in cross section. One of the descending vasa recta (arrowed) shows pathological changes of unknown aetiology $\times 1220$. 
the presence of a countercurrent exchange system in the vascular bundles which can result in the trapping of solutes in the medulla or their exclusion from it. The exclusion of water is obviously important in the maintenance of the osmotic gradient in the medulla but perhaps of more clinical interest is the possible effect of such exchanges on the concentration of drugs in the medulla. Phenazone (antipyrine), for example, is said to be excluded from the medulla, a curious feature in the light of the ability of this drug to produce papillary necrosis.

\section{The interstitial tissue of the medulla}

Finally, I would like to discuss a much neglected subject, namely the interstitial tissue of the medulla. This consists of a copious matrix, rich in glycosaminoglycans, in which are embedded all the tubules and vessels, together with a number of interstitial cells which are associated with the metabolism of various prostaglandins. The matrix itself is of great interest because it is through this medium that all exchanges of water and solute between the tubules and vessels have to take place. One of the puzzling features of the renal medulla is that it has no lymphatics. ${ }^{49}$ It is therefore necessary to consider how the various materials that may enter the interstitium are removed. Most of the water that comes (mainly) from the collecting ducts probably enters the ascending vasa recta, but the fate of the extravascular protein ${ }^{50}$ and of any tubular contents that may enter the interstitium in pathological conditions such as intrarenal reflux need to be investigated. In this respect the work of SchmidtNielsen ${ }^{51}$ is of great potential interest. She injected alcian blue into the papilla $50 \mathrm{~mm}$ from the tip and found that the stain moved up channels around the collecting ducts and beneath the papillary epithelium at about $200 \mu \mathrm{m} / \mathrm{s}$. The channels could be identified in sections both by light and electron microscopy and were about $0.5 \mu \mathrm{m}$ in width. The dye was later found in the interstitial tissue in the outer medulla and in the cortex.

In an effort to discover how extravascular materials might be removed from the medulla, the clearance of ferritin and Imferon from the interstitium has been investigated.52 These were introduced into the medulla of rat kidneys by reflux up the ureter, which causes forniceal rupture, by direct injection with a microneedle; or by intravenous injection. No lymphatics were found by light or electron microscopy. The injected material was taken up by phagocytic cells in the interstitium, in which it could be recognised by means of the Prussian blue reaction for iron. In the inner medulla the iron-containing cells were arranged in isolated longitudinal chains.

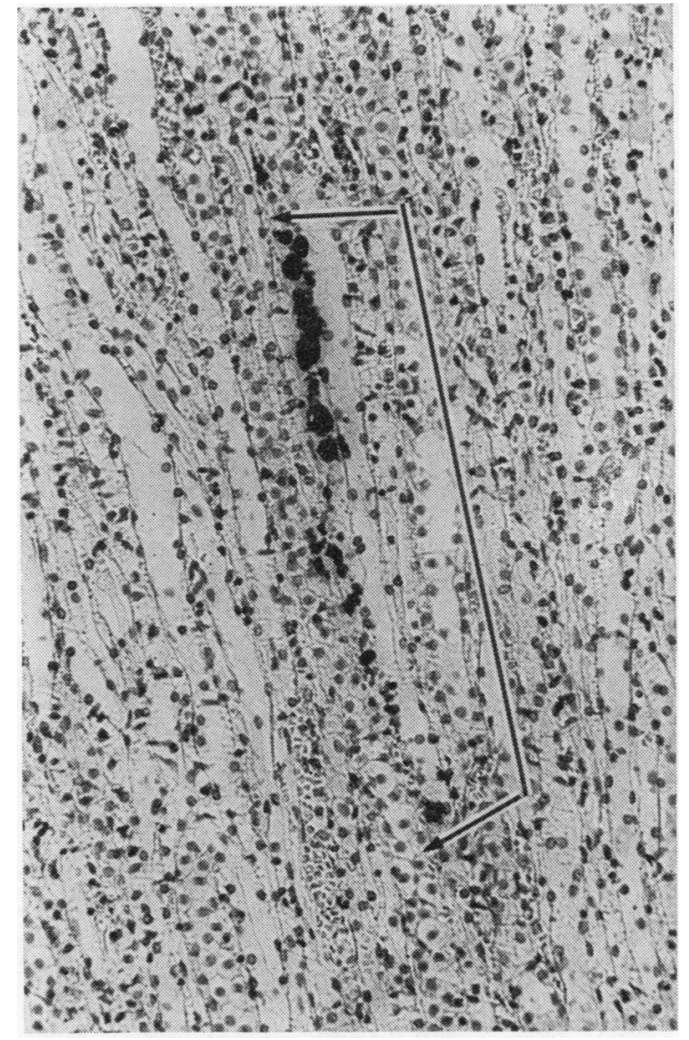

Fig. 3 Rat, inner medulla, 20 min'after the injection of a small quantity of Imferon into the interstitial tissue near the tip of the papilla. The arrows indicate one of the chains of iron-laden cells. The tip of the papilla is towards the bottom. Prussian blue reaction $\times 190$.

usually widely separated, with no cells in the intervening spaces (Fig. 3). The cells were inconspicuous near the tip of the papilla but became larger and more densely packed with iron-containing granules as the chains of cells were followed towards the outer medulla. In the outer medulla itself, clumps of very large cells were found in relation to distended blood vessels packed with blood cells (Fig. 4), probably venous in origin. Here, some of the cells appeared to be passing through the vessel walls and many were found within the vessels (Figs. 4 and 5). Although these cells have been identified by electron microscopy it has not yet been possible to confirm that they pass through the vessel walls or to discover the cause of the vessel distension-it may be that the vessels are partially obstructed by the clumps of huge phagocytic cells within the lumen. It is difficult, also, to understand the disposition of the chains of cells in the inner medulla but the channels 


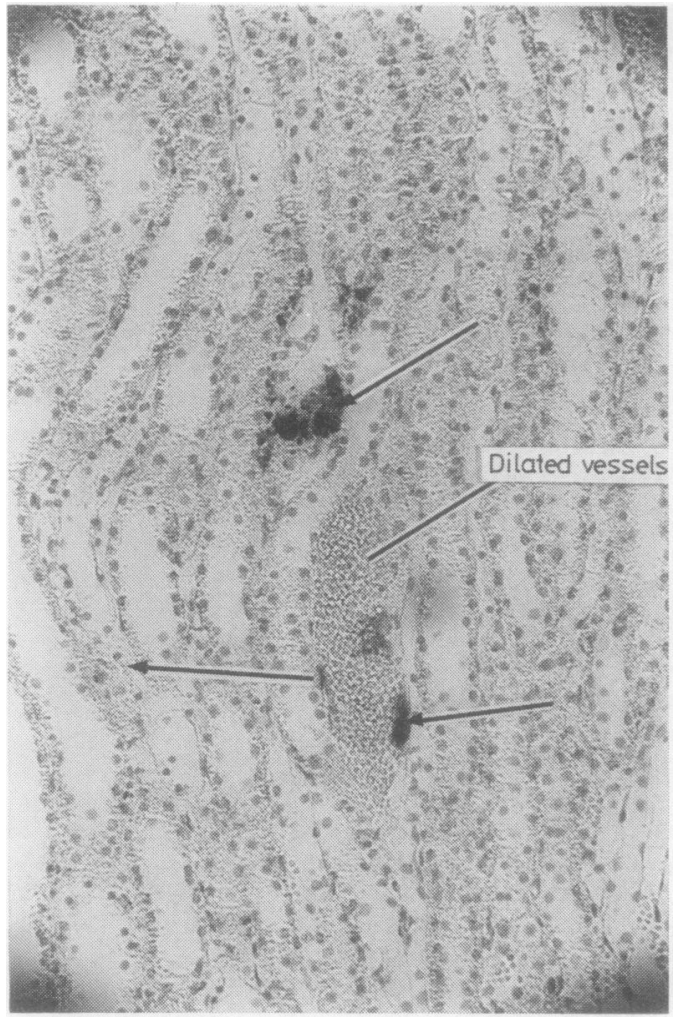

Fig. 4 Rat, outer medulla, 45 min after the injection of a small quantity of ferritin into the papilla. Clusters of cells lie in relation to a distended vessel (arrows) and some appear to be passing into the vessel. Prussian blue reaction $\times 190$. described by Schmidt-Nielsen offer a possible explanation. If the ferritin passes from the interstitium into one or more of the channels around the collecting ducts and thence towards the outer medulla, phagocytic cells along this pathway might pick up the particles along the route, thus causing the linear distribution. It is well known that phagocytosis is inhibited by a high osmolarity so that the amount of iron picked up by the cells would increase towards the base of the papilla.

\section{TAMM-HORSFALL PROTEIN}

An interesting new tool for investigating tubular damage with extravasation of tubular contents into the interstitium is provided by Tamm-Horsfall protein, a peculiar product of renal tubular epithelium. This glycoprotein, which is a constituent of normal urine, has recently attracted a good deal of interest in relation to renal disease. A number of previous authors have studied the distribution in animals $s^{53}$ and recently the human kidney has been studied by Sikri et al. ${ }^{54}$ The latter authors found the protein in relation to the plasma membranes of the thick ascending limb of the loop of Henle and of the distal tubule with the notable exception of the cells of the macula densa, a distribution very similar te that of the animals which have been studied. Apar from its possible physiological importance, the most interesting feature of Tamm-Horsfall protein to pathologists is its role in cast formation and its contribution to extratubular extravasations. While its distribution is normally restricted to the cells mentioned above and to the urine, when the tubules

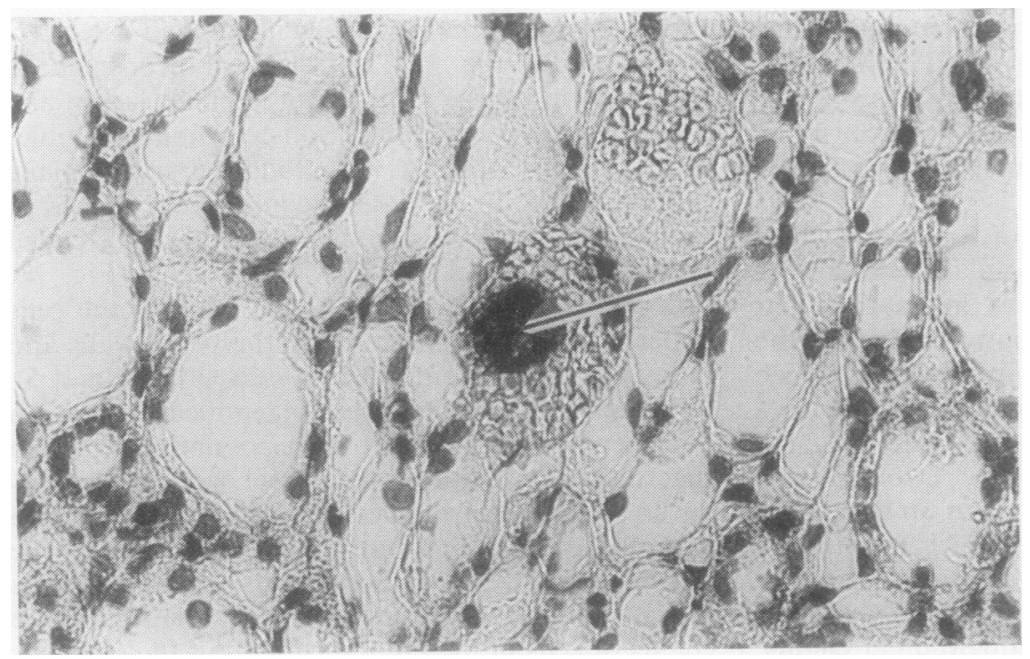

Fig. 5 Rat, outer medulla, one hour after the injection of Imferon into the papilla. $A$ distended vessel contains an iron-laden cell. Prussian blue reaction $\times 480$. 
are damaged it is found in the surrounding tissues and thus acts as an indicator of the site of damage. It has been found in the interstitium in medullary cystic disease and in chronic pyelonephritis while similar deposits have been found in experimental intrarenal reflux in pigs. ${ }^{55}$ The possible effects of this "foreign" protein outside the tubules will, no doubt, be the subject of much further study.

\section{References}

${ }^{1}$ Bowman $\mathrm{W}$. On the structure and use of the Malpighian bodies of the kidney with observations on the circulation through that gland. Philos Trans $R$ Soc Lond (Biol) 1842; 132:57-80.

${ }^{2}$ Latta H, Johnston WH, Stanley TM. Sialoglycoproteins and filtration barriers in the glomerular capillary wall. J Ultrastruct Res 1975;51:354-76.

${ }^{3}$ Kanwar YS, Farquhar MG. Anionic sites in the glomerular basement membrane. J Cell Biol 1979;81:137-53.

* Kanwar YS, Farquhar MG. Presence of heparan sulfate in the glomerular basement membrane. Proc Natl Acad Sci USA 1979;76:1303-7.

${ }^{5}$ Kanwar YS, Farquhar MG. Isolation of glycosaminoglycans (heparan sulfate) from glomerular basement membranes. Proc Natl Acad Sci USA 1979;76:4493-7.

${ }^{6}$ Rodewald R, Karnovsky MJ. Porous substructure of the glomerular slit diaphragm in the rat and mouse. $J$ Cell Biol 1974;60:423-33.

${ }^{7}$ Karnovsky MJ, Ryan GB. Substructure of the glomerular slit diaphragm in freeze-fractured normal rat kidney. J Cell Biol 1975;65:233-6.

${ }^{8}$ Karnovsky MJ. The structural bases for glomerular filtration. In: Kidney disease-present status. IAP monograph No 21. Baltimore: Williams and Wilkins Co, 1979.

9 Trenchev P, Dorling J, Webb J, Holborow EJ. Localization of smooth muscle-like contractile proteins in kidney by immunoelectron microscopy. J Anat 1976;121:85-95.

10 Tyson GE. Scanning electron microscopic study of the effect of vinblastine on podocytes of rat kidney. Virchows Arch B [Cell Pathol] 1977;25:105-15.

11 Andrews PM. The effect of vinblastine-induced microtubule loss on kidney podocyte morphology. Am J Anat 1977;150:53-62.

12 Rennke HG, Venkatachalam MA. Structural determinants of glomerular permselectivity. Fed Proc 1977;36:2619-26.

${ }^{13}$ Chang RLS, Deen WM, Channing RR, Brenner BM. Permselectivity of the glomerular capillary wall: III Restricted transport of polyanions. Kidney Int 1975;8: 212-8.

14 Rennke HG, Cotran RS, Venkatachalam MA. Role of molecular charge in glomerular permeability. Tracer studies with cationised ferritins. J Cell Biol 1975;67: 638-46.

${ }^{15}$ Kanwar YS, Linker A, Farquhar MG. Increased permeability of the glomerular basement membrane to ferritin after removal of glycosaminoglycans (heparan sulfate) by enzyme digestion. J Cell Biol 1980;86:688-93.

${ }^{16}$ Ryan GB, Karnovsky MJ. Distribution of endogenous albumin in the rat glomerulus: role of hemodynamic factors in glomerular barrier function. Kidney Int 1976;9: 36-45.

17 Ryan GB, Hein SJ, Karnovsky MJ. Glomerular permeability to proteins. Effects of hemodynamic factors on the distribution of endogenous immunoglobulin $G$ and exogenous catalase in the rat glomerulus. Lab Invest 1976;34:415-27.

18 Brenner BM, Bohrer MP, Baylis C, Deen WM. Determinants of glomerular permselectivity: insights derived from observations in vivo. Kidney Int 1977;12:229-37.

${ }^{19}$ Seiler MW, Rennke HG, Venkatachalam MA, Cotran RS. Pathogenesis of polycation-induced alterations ("fusion") of glomerular epithelium. Lab Invest 1977;36:48-61.

${ }^{20}$ Andrews PM. Glomerular epithelial alterations resulting from sialic acid surface coat removal. Kidney Int 1979; 15:376-85.

${ }^{21}$ Norgaard JOR. Experimentally induced ultrastructural changes in epithelial cells of isolated glomeruli. Lab Invest $1979 ; 41: 224-36$.

${ }^{22}$ Reeves WH, Kanwar YS, Farquhar MG. Assembly of the glomerular filtration surface. Differentiation of anionic sites in glomerular capillaries of newborn rat kidney. J Cell Biol 1980;85:735-53.

${ }^{23}$ Kanwar YS, Farquhar MG. Detachment of endothelium and epithelium from the glomerular basement membrane produced by kidney perfusion with neuraminidase. $L a b$ Invest $1980 ; 42: 375-84$.

${ }^{24}$ Oberley TD, Mosher DF, Mills MD. Localization of fibronectin within the renal glomerulus and its production by cultured glomerular cells. Am J Pathol 1979;96: 651-62.

${ }^{25}$ Madri JA, Roll FJ, Furthmayr H, Foidart J-M. Ultrastructural localization of fibronectin and laminin in the basement membranes of the murine kidney. J Cell Biol $1980 ; 86: 682-7$

${ }^{26}$ Huang TW. Basal lamina heterogeneity in the glomerular capillary tufts of human kidneys. J Exp Med 1979;149: 1450-9.

27 Barajas L. The ultrastructure of the juxtaglomerular apparatus as disclosed by three-dimensional reconstructions from serial sections.J Ultrastruct Res $1970 ; 33$ : 116-47.

28 Zamboni L, DeMartino C. A re-evaluation of the mesangial cells of the renal glomerulus. Zeitschrift für Zellforschung 1968;86:364-83.

${ }^{29}$ Christensen JA, Bjaerke HA, Meyer DS, Bohle A. The normal juxtaglomerular apparatus in the human kidney. Acta Anat (Basel) 1979;103:374-83.

30 Taugner R, Schiller A, Kaissling B, Kriz W. Gap junctional coupling between the JGA and the glomerular tuft. Cell Tissue Res 1978;186:279-85.

${ }^{31}$ Becker CG. Demonstration of actomyosin in mesangial cells of the renal glomerulus. Am J Pathol 1972;66:97-110.

32 Accinni L, Natali PG, Vassallo L, Hsu KC, DeMartino C. Immunoelectron microscopic evidence of contractile proteins in the cellular and acellular components of mouse kidney glomeruli. Cell Tissue Res 1975;162: 297-312.

${ }^{33}$ Scheinman JI, Fish AJ, Brown DM, Michael AJ. Human glomerular smooth muscle (mesangial) cells in culture. Lab Invest 1976;34:150-8.

${ }^{34}$ Bernik MB. Contractile activity of human glomeruli in culture. Nephron 1969;6:1-10.

${ }^{35}$ Mahieu PR, Foidart JB, Dubois CH, Dechenne CA, Deheneffe J. Tissue culture of normal rat glomeruli: contractile activity of the cultured mesangial cells. Invest Cell Pathol 1980;3:121-8.

${ }^{36}$ Ausiello DA, Kreisberg JI, Roy C, Karnovsky MJ. Contraction of cultured rat glomerular cells of apparent mesangial origin after stimulation with angiotensin II and arginine vasopressin. J Clin Invest 1980;65:754-60.

${ }^{37}$ Osborne MJ, Droz B, Meyer P, Morel F. Angiotensin II: renal localisation in glomerular mesangial cells by autoradiography. Kidney Int 1975;8:245-54. 
3* Michael AF, Keane WF, Raij L, Vernier RL, Mauer SM. The glomerular mesangium. Kidney Int 1980;17:141-54.

${ }^{39}$ Elema JD, Hoyer JR, Vernier RL. The glomerular mesangium; uptake and transport of intravenously injected colloidal carbon in rats. Kidney Int 1976;9: $395-406$.

40 Takamiya H, Batsford S, Kluthe R, Vogt A. Comparison of the handling of ferritin and ferritin-protein conjugates by the glomerular mesangium: genetic studies in the rat. Lab Invest $1979 ; 40: 18-24$.

${ }^{41}$ Lee S, Vernier RL. Immunoelectron microscopy of the glomerular mesangial uptake and transport of aggregated human albumin in the mouse. Lab Invest 1980;42:44-58.

${ }^{12}$ Albertine KH, O'Morchoe CCC. Distribution and density of the canine renal cortical lymphatic system. Kidney Int 1979;16:470-80.

${ }^{13}$ Fourman J, Moffat DB. The blood vessels of the kidney. Oxford: Blackwell, 1971

4 Kaissling B, Kriz W. Structural analysis of the rabbit kidney. Advances in Anatomy, Embryology, and Cell Biology 1979;56:1-123.

1.5 Beeuwkes $R$. The vascular organization of the kidney. Annu Rev Physiol 1980;42:531-42.

${ }^{16}$ Moffat DB. The anatomy of the renal circulation. In: Black D, Jones NF, eds. Renal disease. Oxford: Blackwell. 1979.

17 Beeuwkes R. Vascular-tubular relationships in the human kidney. In: Leaf A, Giebisch G, eds. International
Symposium of Renal Pathophysiology. New York: Raven, 1980.

18 Heaton JM, Bourke E. Papillary necrosis associated with calyceal arteritis. Nephron 1976;16:57-63.

19 Kriz W, Dieterich HJ. Das Lymphgefässsystem der Niere bei einigen Säugetieren. Licht und elektronen mikroskopische Untersuchungen. Z Anat EntwGesch 1970;131:111-47

50 Moffat DB. Extravascular protein in the renal medulla. QJ Exp Physiol 1969;54:60-7.

${ }^{51}$ Schmidt-Nielsen B. Excretion in mammals: role of the renal pelvis in the modification of the urinary concentration and composition. Fed Proc 1977;36:2493-503.

32 Moffat DB. Clearance of extravascular materials from the renal medulla. Ann $R$ Coll Surg Engl 1979;61:315.

${ }^{33}$ Hoyer JR, Seiler MW. Pathophysiology of TammHorsfall protein. Kidney Int 1979;16:279-89.

"Sikri KL, Foster CL, McHugh N, Marshall RD. Localization of Tamm-Horsfall glycoprotein in the human kidney using immunofluorescence and immunoelectron microscopic techniques. J Anat 1981;132:597-605.

5.) Cotran RS, Hodson CJ. Extratubular localization of Tamm-Horsfall protein in experimental reflux nephropathy in the pig. In: Hodson J, Kincaid-Smith P. eds. Reflux nephropathy. New York: Masson, 1979.

Requests for reprints to: Prof. DB Moffat, Department of Anatomy, University College, Cardiff, Wales. 